\title{
Sustainable world through sustainable materials and integrated biorefineries
}

\author{
Said Salah Eldin Elnashaie • Firoozeh Danafar • \\ Fakhru'l-Razi Ahmadun
}

Received: 24 June 2013/Accepted: 2 October 2013/Published online: 19 November 2013

(C) The Author(s) 2013. This article is published with open access at Springerlink.com

\begin{abstract}
The present world, with all its advancement, is not a sustainable world, simply because it is based on nonrenewable raw materials (non-RRMs). Sustainable world is best expressed in terms of sustainable development and non-RRMs must be replaced by sustainable materials. The sustainable materials needed by modern society are very wide and the main pillars are biofuels and bioproducts. Both pillars are best related through integrated biorefineries (IBRs) formed of related concepts which are very important for the economic development and sustainability of all countries on our planet. Integrated biorefineries include the production of biofuels and bioproducts and utilizing novel technologies. An IBR contains at least two routes: a biochemical route based on a sugar platform and a thermochemical-catalytic route based on a syngas platform. It is a multiple inputs-multi outputs (MIMO) system with design flexibility to accept a wide range of biofeedstock, especially wastes. If the biorefinery consists of only one route/ platform, or is limited with regard to MIMO or biofuels/ bioproducts produced, then it should be considered an elementary biorefinery (EBR). Sustainable development engineering which is a subsystem of sustainable
\end{abstract}

S. S. E. Elnashaie $(\bowtie) \cdot$ F.-R. Ahmadun

Department of Chemical and Environmental Engineering,

Faculty of Engineering, Universiti Putra Malaysia,

43400 Serdang, Selangor, Malaysia

e-mail: selnashaie@gmail.com

F. Danafar

Department of Chemical Engineering, College of Engineering, Shahid Bahonar University of Kerman, 7618891167 Kerman, Iran

S. S. E. Elnashaie

Chemical and Biological Engineering Department, University of British Columbia (UBC), Vancouver, Canada development (and sustainable world) is more general than Environmental Engineering; and Clean and Green Technology, because it also includes the utilization of RRMs to achieve not only sustainability but also clean environment. An integrated system approach based on system theory is used to analyse sustainable development, sustainable world, sustainable materials, IBRs, EBRs and their interactions.

Keywords Sustainable - Integrated biorefineries (IBR) · Biofuels · Renewable raw material (RRM)

\section{Introduction}

System theory [1-17] is the basis of the integrated system approach, which is the most efficient methodology for knowledge classification, organization, transfer, and exchange [18]. The integrated system approach is very valuable in both research and education. In research, it is one of the most important tools for the development of new knowledge and novel processes, especially in areas where multi-disciplinary research and development is a must for innovative solutions $[19,20]$. Sustainable development is one of those areas that are multi-disciplinary by their very nature [21]. It is formed by a number of sub-systems, each of which is formed by its own elements (or subsystems of subsystems depending upon the level of analysis). Subsystems of sustainable development include both technical and non-technical categories, for example, technology, socioeconomic, political, ethical/moral, and so on. Focusing on any one of the sustainable development subsystems can only be successful within a framework that has the other subsystems as a background. Within the technological subsystem of sustainable development, a structural 
hierarchy of subsystems, followed by subsystems of subsystems, down to elements gives the structure and boundaries of this important subsystem, especially from an engineering point of view. It is useful in this regard to use terminologies and classifications of system theory coupled with terminology of non-linear dynamics and stability theorem. As an example, we can consider efficient engineering as a subsystem of environmental engineering, representing a necessary but not sufficient condition for Clean and Green Technology (C\&GT). This is due to the simple fact that applying efficient engineering without taking environmental constraints into consideration can achieve maximum productivity that would not necessarily be environmentally clean. C\&GT will need efficient engineering as a prerequisite. Also, we can consider Environmental Engineering as a subsystem of sustainable development engineering, representing a necessary but not sufficient condition for sustainability. This is due to the simple fact that Environmental Engineering without using RRMs can achieve C\&GT and maximum productivity but is not necessarily sustainable.

Sustainable development engineering will have both efficient and environmental engineering as prerequisites. The utilization of RRMs is at the heart of sustainability; this leads to the crucial importance of biofuels at one level and IBRs at higher levels, as discussed in this article, using the integrated system approach as an efficient tool. Although, biofuels from RRMs are very useful for a cleaner environment, it is not sufficient for sustainable development, which needs both biofuels and bioproducts produced from RRMs, therefore, requiring IBRs. This need of sustainable development and its coupling to IBRs and RRMs suggests other needs for new technologies and innovative solutions to old and new challenges as well as novel technologies for RRMs. It is also important to take into consideration the fact that RRMs are geographically usually spread over wide areas while classical non-RRMs are usually concentrated in certain areas; this will have important effect on the technology of getting the raw materials to the processing plant and the optimal layout of the processes and the plant. Novel technologies will need to be utilized to the most to make packages of RRMs with their novel technologies compete with classical non-RRMs and their well established technologies. For the first package to win the competition it has to use research extensively and utilize optimal coupling between experimental techniques and mathematical/computer modelling in the development and scaling up of novel technologies. The theme of this article is to stress the importance of the system theory when dealing with the issue of sustainability, biofuels (BFs), and IBRs. In this respect, an introduction will be presented about system theory, and then the focus is on the how sustainable development (SD) relates to the system theory (ST) and integrated system approach (ISA).

\section{System theory}

\section{System theory}

System theory is a basic tool for dealing with sustainability and sustainable development, and hence it should be more widely used in engineering education and research. In this respect, definitions of some important terms are essential. First of all, what is a system? The word system derives from the Greek word systema and means an assemblage of objects united by some form of regular interaction or interdependence [17, 19]. A simpler, more pragmatic description regarding systems includes the following:

- A system is a whole composed of parts (elements or subsystems).

- The concepts of a system, subsystem, and element are relative and depend upon the degree of analysis.

- The parts of the system can be parts in the physical sense or they can be processes. A system can be formed of both (i.e. different parts of the system; a reactor and a regenerator combined to form a fluid catalytic cracking unit) [16], each part having a number of processes taking place within its boundaries.

- The properties of the system are not necessarily the sum of the properties of its components (elements or subsystems), although they are, of course, affected by those components. Instead, the properties of the system result from non-linear interaction (synergy) between elements or subsystems [17, 19].

\section{The state of the system and state variables}

The term state of the system, rigorously defined through the state variables of the system, is used extensively in discussing and modelling/simulation of systems. These state variables are chosen according to the nature of the system.

\section{Input variables (parameters)}

Input variables are not state variables. Instead, they are external to the system but affect the system (i.e. work on the system). For example, the feed temperature and composition of the feed stream to a distillation tower or a chemical reactor or the feed temperature to a heat exchanger are input variables. 


\section{Design variables (parameters)}

They are associated with the design of the system and are usually fixed. Examples are the diameter and height of a continuous stirred tank reactor (CSTR) or of a tubular reactor.

\section{Boundaries of system}

A system has boundaries distinguishing it from the surroundings or environment. The relation between the system and its environment leads to one of the most important classifications of systems:

Isolated systems They do not exchange matter or energy with the environment (surroundings). They tend to the state of thermodynamic equilibrium (maximum entropy). An example is a batch adiabatic reactor.

Closed systems They do not exchange matter with the environment (surroundings), but they do exchange energy. Such systems, again, tend to thermodynamic equilibrium (maximum entropy). A batch non-adiabatic reactor is an example.

Open systems They exchange matter and energy with the environment (surroundings). They do not tend to thermodynamic equilibrium but to steady state or what should better be called a stationary non-equilibrium state, characterized by minimum entropy generation. A CSTR is an example.

The above shows that the term steady state commonly used in chemical/biological engineering and other disciplines is not precise enough. A more accurate term should be stationary non-equilibrium state, which is a characteristic of open systems, distinguishing it from stationary equilibrium state, associated with isolated and closed systems.

\section{Steady and unsteady states and thermodynamic equilibrium of systems}

Steady state occurs when the state of the system does not change with time, but the system is not at thermodynamic equilibrium. This steady state of lumped systems is a point in a space having the same dimensions as the problem (number of components + temperature + pressure, etc.), whereas that for distributed systems is a profile in the space coordinate(s) as additional dimension(s). Unsteady state of an open system starts at an initial condition and tends with time towards a steady state when the system is stable (a point for lumped system and profile for distributed systems).

\section{Integrated system approach}

Sustainable development in a changing global environment will require resilience at many levels, including human communities and economic enterprises. In the face of everincreasing global complexity and volatility, it is essential to move beyond a simplistic steady state model of sustainability. Instead, we need to develop adaptive policies and strategies that enable societal and industrial institutions to cope with unexpected challenges, balancing their need to be able to achieve an efficient sustainable development. The current lack of success in improving industrial sustainability, coupled with the challenges of biocomplexity and resilience, indicates that sustainability is a system's problem requiring collaborative solutions with a crossdisciplinary nature $[12,22,30,44,46,48,51-54,58,59]$. A number of technical advances will likely improve the usefulness of models, including rigorous methodologies for dealing with missing and uncertain information; improved methods for interpretation of multivariate data sets and for multi-objective decision making involving trade-offs among conflicting goals; and novel modelling methods as alternatives to traditional mathematical models. More generally, there is a great need for operational definitions and metrics for sustainability and resilience in economic, ecological, and societal systems.

Basic principles of sustainable development

The simple analysis in the introduction and some other components discussed in this article highlight the following basic principles:

1. Sustainable development is a system formed of technological and non-technological subsystems with the following components as the principle ones:

(a) Political (e.g. legislations and strategic decisions...).

(b) Economical (e.g. investment in novel new technologies).

(c) Social, ethical/moral (e.g. consumption trends, acceptance of novel clean technologies and products, moral/ethical factors).

(d) Technological (e.g. novel efficient clean technologies, clean fuels, efficient utilization of renewable feedstock, new environmentally friendly products, in-process modification for minimum pollution maximum production (MPMP), efficient waste treatment) with special emphasis on the technological subsystem with the other subsystems in the background.

2. Sustainable development engineering is a subsystem of the technological subsystem of sustainable development.

3. Sustainable development can also be divided into the following [24, 27, 29, 34, 39, 41].

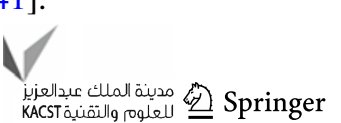


(a) Sustainable development with respect to production, which is the main emphasis of this article.

(b) Sustainable development with respect to consumption, which is in the background of this article.

Sustainable production and consumption (SP\&C) emerged as a key issue on the sustainable development agenda at the UN Conference on Environment and Development (UNCED) in Rio de Janeiro in 1992. The agenda called on governments, businesses, and others to implement measures to promote efficiencies in production and encourage sustainable patterns of consumption. It went on to say that the developed countries should take the lead in introducing those measures. An international agenda had been introduced by the UN Commission on Sustainable Development (UNCSD), in cooperation with national governments; the Organization for Economic Cooperation and Development (OECD) and others responded to this mandate with an international work programme and recommendations for action. Proposed action items included the following:

- Pricing reforms to internalize environmental costs and remove subsidies that generate unsustainable consumption

- "Green" public procurement policies

Main actions taken for sustainable development include:

- Extending producer responsibility for the lifecycle environmental impacts of goods and services

- Eco-labelling programmes

The UNCSD has called specifically upon businesses to do the following:

- Integrate environmental criteria into their purchasing policies

- Design more efficient products and processes

- Increase the life-spans for durable goods

- Improve their after-sales services, reuse, and recycle

- Promote sustainable consumption through advertising, marketing, and product information

4. Efficient engineering is a subsystem of environmental engineering, and environmental engineering is a subsystem of sustainable development engineering. In other words, efficient engineering is necessary but not sufficient for environmental engineering, and environmental engineering is necessary but not sufficient for sustainable development engineering.

5. Metrics are necessary for measuring sustainability [31, $55]$.

According to the extensive study by the IChemE, metrics for sustainability can be divided into three groups: environmental indicators, economic indicators, and social indicators. This emphasizes, however, the three categories do not show explicitly the importance of RRMs for sustainability, shown very simply and briefly above. RRMs represent a crucial component of sustainable development engineering and, thus, sustainable development and C\&GT based on non-RRMs may be satisfactory from an environmental engineering point of view but is not sustainable. Biofuels [15] are an important subsystem of renewable clean energy, others are wind energy, solar energy, etc. There are a large number of biofuels; each one of them can be produced through different routes. Figure 1 shows some of these routes for biodiesel and biohydrogen. All biofuels and all technologies will have their positions in the clean fuels matrix of the future.

Figure 1 shows two types of biodiesels, the strategic Fischer-Tropsch biodiesel from syngas [4, 36, 45] and the non-strategic biodiesel from the transesterification of vegetable oils. A third type of biodiesel, which is proving to be more strategic than both, is the algae biodiesel [2, 6, $13,14,23,35,47,50]$. Among the most photosynthetically efficient plants are those various types of algae. Some species of algae are ideally suited to biodiesel production due to their high oil content (some well over $50 \%$ oil) [7, $13,35]$ and extremely fast growth rates, 200 times faster than soya bean [20]. Extensive research is carried out now on the growth of specially chosen strains of microalgae [3, $28,40,49]$ in optimally designed and operated photobioreactors [3].

\section{Integrated bioreactors}

An IBR is a complex facility that integrates biomass conversion processes and equipment to produce fuel, power, and chemicals/biochemicals from the biomass. It is analogous to today's petroleum refineries and its integrated petrochemical complexes, which produce multiple fuels and products from petroleum. IBRs have been identified as the most promising route to the creation of a new domestic and distributed bio-based industry. Sustainability does not depend only on sustainable fuels but also on sustainability of other commodities for modern societies. This important simple fact leads to the important concept of IBRs [39] producing not only sustainable fuels but also other sustainable commodities and energy. The National Renewable Energy Laboratory, which is a part of the USA Department of Energy (DOE), defines biorefinery as "a facility that integrates biomass conversion processes and equipment to produce fuels, power, and chemicals from biomass." The present view about IBRs is based on two platforms, the sugar platform and syngas platform, as discussed later. Production facilities for sustainable biofuels are a subsystem of IBRs. The implications of this are as follows: 
Fig. 1 Some routes to biodiesel and biohydrogen

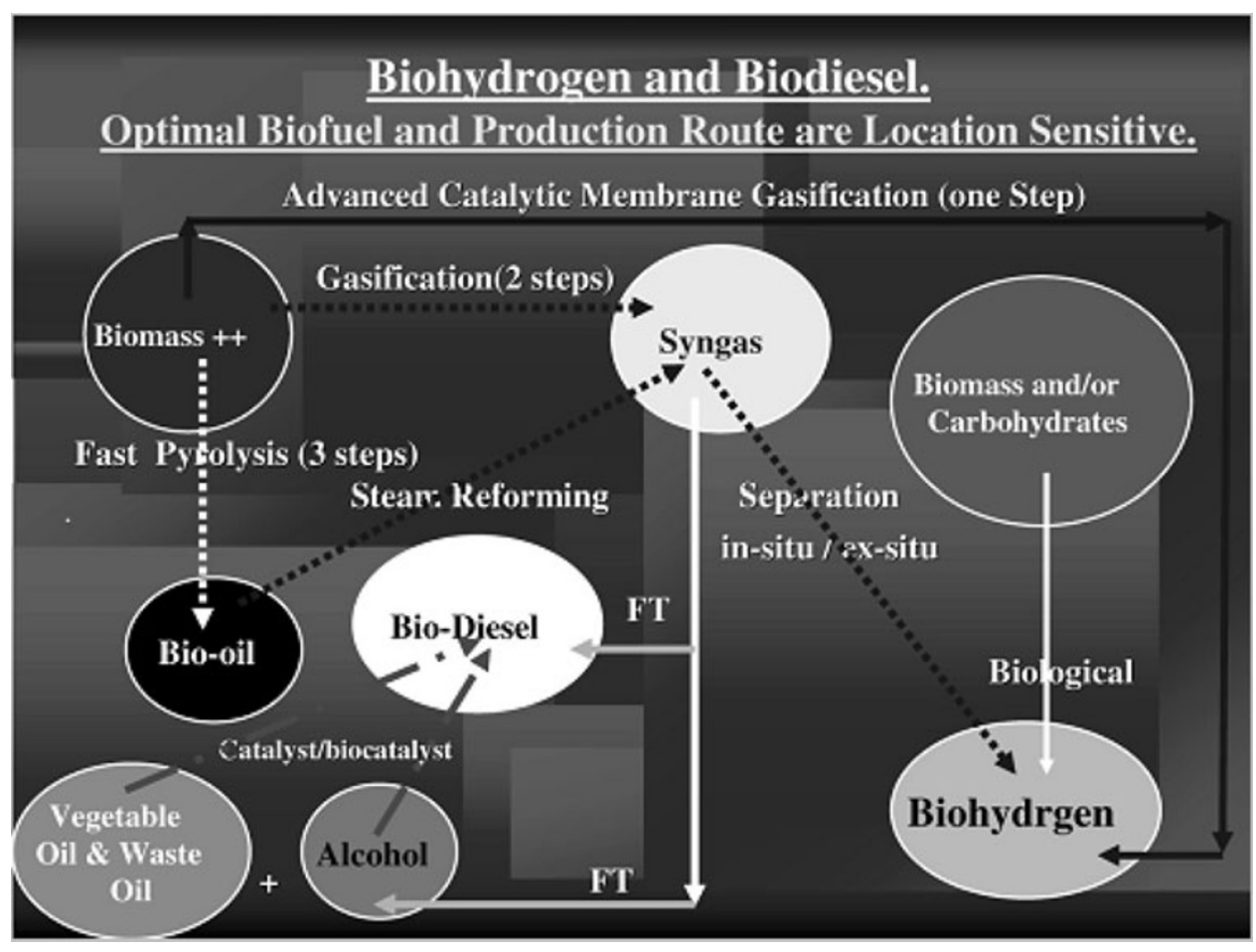

- A sustainable biofuels facility built today should be planned with its growth into an IBR in mind.

- Sustainable biofuel production will almost always be a part of IBRs.

- An advanced definition of IBRs and their subsystems should be developed together with a clear definition of biofuels and bioproducts.

- A clear definition of sustainability and quantification of these definitions into suitable metrics should be developed.

Both the National Science Foundation (NSF) and DOE are putting large research funds into development of IBRs $[1,5,8-10,25,26,32,33,42,43,61]$.

IBRs represent an integral critical subsystem of sustainable development, which is a multi-disciplinary system by its very nature, as discussed earlier. It is best to use the integrated system approach to study this complex multidisciplinary system and its subsystems. Engineers are most interested in the technology part (which is a subsystem of the sustainable development system) but with a background understanding of other subsystems and collaboration with other disciplines, as discussed earlier. Also discussed earlier, sustainable development engineering is the most important subsystem of the technology part, which is itself a subsystem of the sustainable development system. As discussed earlier, the efficient utilization of RRMs is at the heart of sustainability. RRMs should be defined very clearly, for this is strongly related to the cycle of renewability, that is, fossil fuels are renewable, but over a cycle of hundreds of thousands (or even millions) of years. A RRM should be renewable over a period of 6-18 months. RRMs can be any kind of renewable waste, for example, agricultural waste, municipal waste, and so on, or special (energy) crops produced specifically to be used for this purpose, for example, switchgrass cultivated and produced especially for biofuels. On the other hand, useful agricultural products used today for biofuels, for example, corn for ethanol, vegetable oil for transesterification to biodiesel, etc., are not acceptable as RRMs because of the consumption of important edible products at a time of food shortage everywhere, especially in developing nations.

Renewable biomass, the main group of RRMs, is a storage tank for solar energy through biosynthesis, $\mathrm{CO} 2$, and other nutrients. The ultimate aim for biofuels is to produce as much $\mathrm{CO} 2$ as consumed in the biosynthesis of the biomass that produced it. This, with maximum efficiency, may lead to approaching zero net $\mathrm{CO} 2$ emission. We cannot really dispose of any $\mathrm{CO} 2$ resulting from fossil fuel; it only keeps circulating from one form/place to the other, except with sequestration by injection under the bottom of the ocean, which is expensive. Its side effects are not known and can only be practised by very large companies. All other techniques just move the $\mathrm{CO} 2$ from one location/to the other without reducing the earth $\mathrm{CO} 2$ added inventory from the carbon source that came from under the ground.

Hydrogen is a good clean fuel and will occupy its part in the clean fuels matrix and is, therefore, one of the potential 
products of IBRs. However, although the claim that it is $100 \%$ clean is locally true, it is actually not globally true if its source is fossil fuel, whether directly through catalytic steam reforming (CSR) $95 \%$ of hydrogen produced in United States is through CSR or indirectly through production of electricity ( $90 \%$ of electricity in the United States is from coal) followed by electrolysis. It can be globally clean only if the source is bio, wind, hydro, nuclear, etc.

The range of fermentable sugars is expanding due to the development in microbiology (specially genetic engineering) and the discovery of efficient mutated microorganisms capable of fermenting the wide range of sugars produced from cellulose/hemicellulose hydrolysis. A strong challenge with lots of intensive research nowadays is in the field of efficient and clean hydrolysis of cellulose/hemicellulose to sugars suitable for fermentation with classical microorganisms and/or mutated ones. Important improvements are achieved in the enzymatic hydrolysis of cellulose/hemicellulose. The process of fermentation is improving continuously using novel membrane immobilized fermenters and novel modes of operation. Lignin from lignocelluloses is used as a cheap fuel to improve the energy efficiency of the IBRs; however, the future potential is to use it as a platform for a wide range of products to replace certain petroleum refining and petrochemical products. Important improvements are introduced to syngas production from biomass through both a one-step process (biomass gasification to syngas) and a two-step process (biomass fast pyrolysis to bio-oil followed by CSR of biooil to syngas). The two-step process seems to be better with regard to the percentage of $\mathrm{H} 2$ in the syngas. Certain difficulties associated with CSR of bio-oil are solvable through novel reformers configurations such as circulating fluidized bed (CFB) CSR. An important challenge in the biomass to FT biofuels process is the integration of the endothermic CSR process with the exothermic catalytic FT process into one integrated membrane catalytic autothermal process. This auto-thermic process can also be integrated to a fluidized bed catalytic chemical vapour deposition (FBCCVD) that will utilize $\mathrm{CO} 2$ as the feedstock and produce the very valuable carbon nanotubes and oxygen to be used in the catalyst regeneration for the CFB CSR. This part of a process can be considered an elementary biorefineries (EBR) and is described very shortly below.

Novel membrane catalytic reactor for catalytic steam reforming coupled to catalytic Fischer-Tropsch process and the novel over all reactor coupled to a novel process to crack $\mathrm{CO} 2$ to carbon nanotubes and oxygen coupled membrane reactors could also make a positive contribution to meet the challenge of sustainable development. This example is dedicated to treatment of one or more intermediates, produced thermochemically from biomass, to produce biofuels that could replace blends of gasoline, diesel, or jet fuels, as well as bioproducts and other liquid hydrocarbons suitable to be fed to existing petroleum refineries (biocrude oil). These intermediates and products include fast pyrolysis bio-oil, syngas, ethanol, mixed alcohols, mixed oxygenates ( $\mathrm{C} 2$ and higher), olefins, ethers, biofuels, biofuels, biocrude oil, etc. This combination of integrated thermo-chemical-catalytic (TCC) processes can be considered EBRs in contradistinction to IBRs which include both TCC as well as biochemical processes refineries. IBRs are large-scale complex systems addressing not only efficient production of a range of biofuels, but also numerous bioproducts. Moving beyond ethanol to higher hydrocarbons, biofuels are becoming increasingly important as blend barriers are reached. Renewable refinery feedstocks biocrude oil could reduce dependence on imported oil by replacing fossil fuels. This could allow progress beyond renewable gasoline-only blending components, and it could also redirect oxygen present in thermo-chemically-derived intermediates to value-added co-products with economic benefits. The oxygen issue is critical and can be addressed through different pathways. The pathway in this example consists of:

1. Extracting oxygen in fast pyrolysis bio-oil and syngas as $\mathrm{CO} 2$.

2. Using catalytic fluidized bed chemical vapour deposition reactors to re-carbonize $\mathrm{CO} 2$ into carbon nanotubes and oxygen.

3. Using oxygen to oxidize intermediates to biofuels and other bioproducts, as well as in the regeneration of catalyst(s).

Advancing these technologies includes choosing process operating parameters to achieve maximum products yields, integrity of process materials of construction, and longterm long life catalyst performance to fit the biomass feedstock. This is the best achieved by optimal coupling of experimental techniques, reactor modelling and computer simulation in novel configurations and catalytic processes. Coupled membrane catalytic reactors represent the heart of many of these processes, as shown below, in Fig. 2. This example focuses on a relatively simple, but novel, integrated biorefinery IBR to produce a wide range of products and advanced materials. Reactor modelling and computer simulation need to be combined with experimental results to achieve system viability. A simplified schematic diagram of the proposed process is shown in Fig. 2, where the starting feed is the bio-oil obtained from biomass through fast pyrolysis. Biomass such as corn stover, woody materials or rice straw is fast pyrolysed, and the resulting bio-oil (fast pyrolysis bio-oil, FPBO) is transformed into syngas in a novel catalytic Circulating fluidized bed membrane steam 


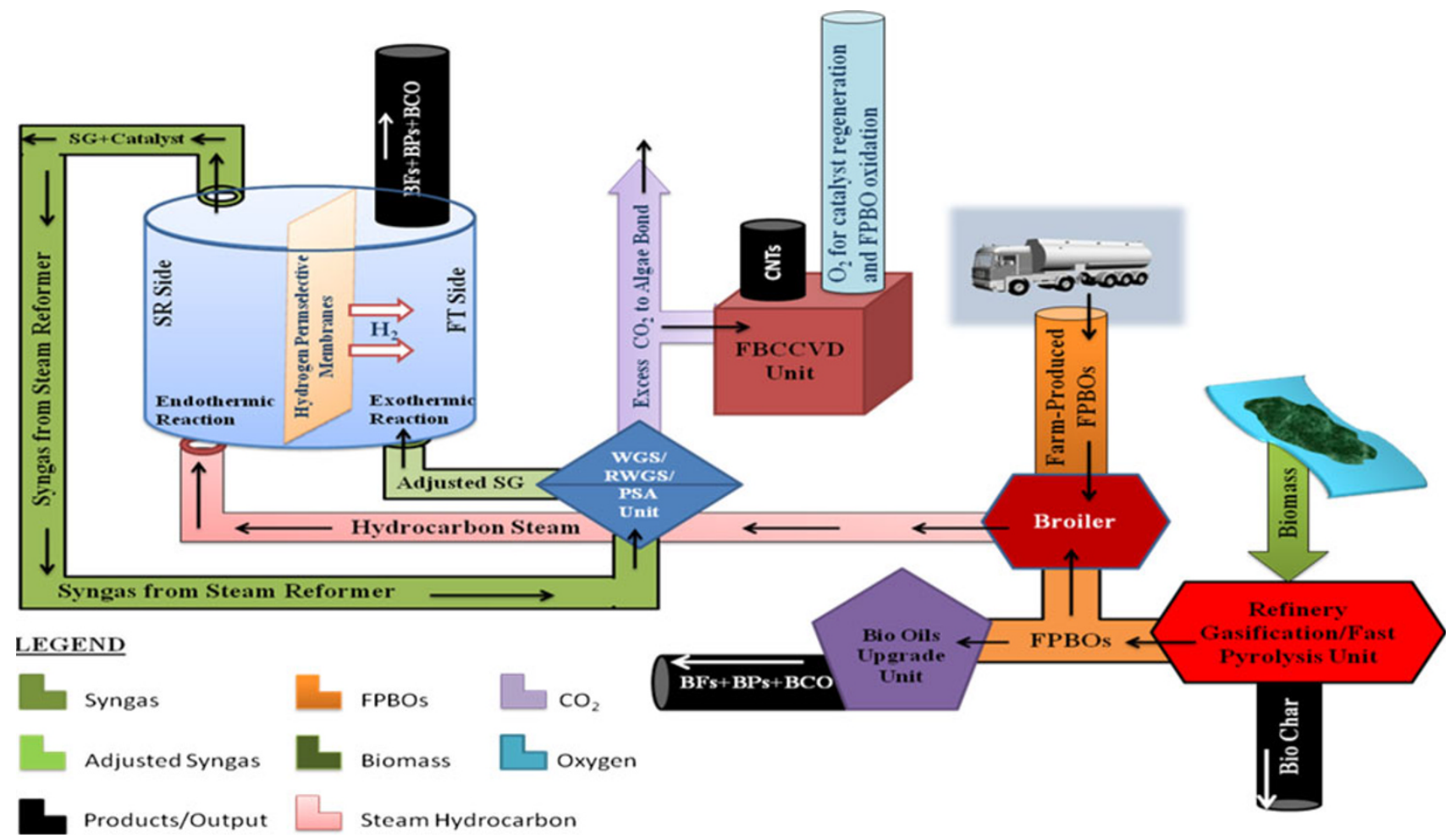

Fig. 2 Simplified diagram for the proposed units at the refinery

reformer (CFBMSR). The syngas then goes to reaction using novel efficient catalytic Fischer-Tropsch processes and catalyst(s) (e.g. nanoparticle catalysts). Other sources of syngas are also considered as shown in Fig. 2. Both CO and $\mathrm{H} 2$ from the steam reforming process transfer to the Fischer-Tropsch reactor through the selective membrane coupling them. The remaining $\mathrm{CO} 2$ is treated together with that resulting from catalyst regeneration as described below. Pre-treatment other external syngas is pre-treated processes, to optimize its composition. This will include to be done using a catalytic reverse water-gas-shift reactor to transform $\mathrm{CO} 2$ to $\mathrm{CO}$, and $\mathrm{CO} 2$-absorption-desorption in a pressure swing adsorption unit to remove any excess $\mathrm{CO} 2$ in the feed to the Fischer-Tropsch unit. This excess $\mathrm{CO} 2$ together with all the $\mathrm{CO} 2$ from the CFBMSR will be treated in a novel catalytic fluidized bed chemical vapour deposition reactors unit to produce CNTs and oxygen.

It is worth mentioning, here, that the extraordinary properties of CNTs and its wide range of applications have encouraged considerable efforts to synthesize this valuable material. $\mathrm{CO} 2$ is a cheap, abundantly available and renewable feedstock that can be converted into highly added-value carbon nanostructures with high carbon yields. Besides that, $\mathrm{CO} 2$ shows great potential as oxidizing agent for improving the quality of CNT synthesis $[11,37,38,56,60,62]$ and enables to catalytically decompose amorphous carbon by the reverse
Boudouard reaction. Taking into account that for most applications, highly pure CNTs are required dictates that impurities should be removed during a post-synthesis step. As purification procedures may affect the structure of CNTs [57], much effort is still put into the development of a direct low temperature synthesis route of highquality CNTs. Using the excess $\mathrm{CO}_{2}$ to produce CNTs and/or bioproducts through photobiosynthesis will depend upon many economical and technological factors.

The $\mathrm{O}_{2}$ will in turn be partly used to oxidize fast pyrolysis bio-oil FPBO to additional biofuels and bioproducts, and partly to regenerate the steam reforming catalyst in the CFBMSR. As shortly mentioned above the CFBMSR is coupled to the Fischer-Tropsch reactor through membranes which allow the transfer of $\mathrm{CO}$ and $\mathrm{H} 2$ from the CFBMSR to the Fischer-Tropsch reactor as well as heat in the opposite direction from the exothermic reactions in the Fischer-Tropsch reactor to the endothermic reactions in the CFBMSR and the unreacted syngas SG from the Fischer-Tropsch unit reactor will be recycled to the reverse water-gas-shift unit. Use of fluidized beds for the catalytic processes will increase efficiency and facilitate on-line sampling and characterization of the different catalysts during the different stages of process development to reach the commercial scale.

The EBR needs to be started up by a special procedure. Each catalytic reactor must then operate at steady state for 
at least $2,000 \mathrm{~h}$ ( 3 months) with a single catalyst loading. This will require a good control system for each unit and for the overall biorefinery. In addition to on-line measurement of state variables, small samples will need to be withdrawn and analysed during operation to follow changes in state variables, including catalyst characteristics. If this EBR is integrated to other lignocelluloses to biofuels EBR based on the sugar platform, this integration of these two EBRs results in an IBR. IBRs should be able to contribute to sustainability and not only renewable biofuels. It is important for IBRs to include all that is bio, whether with regard to feedstock, processes, or both, for instance,

- Biomass utilizing sequential thermal catalytic processes to produce FT biodiesel (the processes are not bio, but the feedstock is bio)

- Biological treatment of $\mathrm{CO}$ and water to produce $\mathrm{CO} 2$ and hydrogen (biocatalysed water-gas shift) reaction; the feed is not bio, but the process is bio)

- Lignocelluloses utilizing sequential bioprocesses to produce cellulosic bioethanol (both feedstock and processes are bio)

- Utilization of bioprocesses to transfer one form of energy to another, for example, integrated bioenergy to biofuel cells (IBE-BFCs) to change intermittent solar energy into continuous electric energy, for many applications including auto-thermal housing IBRs can either grow with time as parts of existing plants (e.g. pulp and paper industry) or start as an IBR based on renewable fuels production and grow into a complete IBR. Other forms of renewable classical energy (RCE) (when suitable, e.g. wind energy) can be integrated with the biofuels to generate the total renewable energy profile of an IBR. The central intermediates (platforms) for the biofuels part of the IBRs seem to be fermentable sugars suitable for fermentation to bioethanol and/or biobutanol and syngas suitable for both hydrogen extraction and use in the Fischer-Tropsch process for producing fuels from methanol up to diesel. It is important, also, to notice that it is possible to combine the gasification of biomass (or fast pyrolysis followed by catalytic steam reforming (CSR) of the product biooil) to produce biosyngas with the fermentation of this biosyngas to produce bioethanol and or biobutanol. Direct utilization of solar energy through different direct techniques (e.g. photocells) without passing through the biosynthesis stage is a possibility, but it has its own bottlenecks and should be integrated with other technologies (e.g. IBE-BFCs) to fully utilize it as a part of auto-thermal housing and IBRs. From the above, it is clear that neither single biofuel nor one technology will dominate for any single one of these biofuels. Humanity will move from today's matrix of dirty, non-renewable

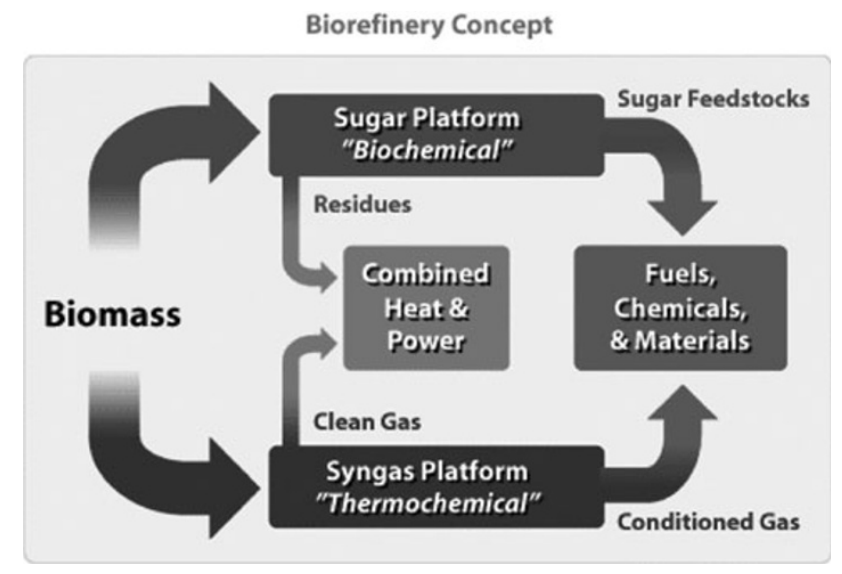

Fig. 3 Preliminary biorefinery structure with the main two sugar and syngas platforms

fuels to a future matrix of clean, renewable fuels, with the sub-matrix of different biofuels from different technologies occupying a large portion of the clean fuels matrix, and that sustainability will not be achieved through biofuels only but should be extended to IBRs, combining biofuels and other bioproducts with efficient bioenergy to achieve sustainable development. Figure 3 shows a simple schematic diagram of an IBR formed of only two platforms; the sugar and syngas platforms as the bioenergy is an integral part of any IBR. It can be considered an integration of two EBRs, and should be optimized with regard to RRMs utilizations and useful biofuels and bioproducts production with minimum to zero emissions.

\section{Conclusions}

Today's matrix of dirty, non-renewable fuels is moving to a future matrix of clean, renewable fuels, with the sub-matrix of different biofuels from different technologies occupying a large portion of the clean fuels matrix. To achieve sustainable development, biofuels processes should be extended to IBRs, combining biofuels and other bioproducts with efficient bioenergy. IBRs represent an integral critical subsystem of sustainable development, which is a multidisciplinary system by its very nature. It is best to use the ISA to study this complex multi-disciplinary system and its subsystems. Engineers are most interested in the technology part (which is a subsystem of the sustainable development system) but with a background understanding of other subsystems and collaboration with other disciplines.

The utilization of RRMs is at the heart of sustainability for biofuel production. It leads to the crucial importance of biofuels at one level and IBRs at higher levels using the 
integrated system approach as an efficient tool. Although, biofuels from RRMs are very useful for a cleaner environment, it is not sufficient for sustainable development which needs both biofuels and bioproducts produced from RRMs, therefore, requiring IBRs. This need of sustainable development and its coupling to IBRs and RRMs suggests other needs for new technologies and innovative solutions to old and new challenges as well as novel technologies for RRMs. Novel technologies will need to be utilized to the most to make packages of RRMs with their novel technologies compete with classical non-RRMs and their well established technologies. For the first package to win the competition it has to use research extensively and utilize optimal coupling between experimental techniques and mathematical modelling in the development and scaling up of novel technologies.

The current lack of success in improving industrial sustainability, coupled with the challenges of biocomplexity and resilience, indicates that sustainability is a system's problem requiring collaborative solutions with a multi-disciplinary nature. There is a great need for operational definitions and metrics for sustainability and resilience in economic, ecological, and societal systems. In this respect, the importance of the system theory is evident that emphasis it should be more widely used in engineering education and research.

Open Access This article is distributed under the terms of the Creative Commons Attribution License which permits any use, distribution, and reproduction in any medium, provided the original author(s) and the source are credited.

\section{References}

1. Aguilar A, Bochereau L, Matthiessen-Guyader L (2008) Biotechnology and sustainability: the role of transatlantic cooperation in research and innovation. Trends Biotechnol 26(4): $163-165$

2. Alvarado P (2007) Biodiesel from algae and the biofuels discussion in Argentina. http://www.treehugger.com/files/2007/03/ biodiesel_from_1.php. Retrieved Aug 2007

3. Arudchelvam Y, Nirmalakhandan N (2012) Optimizing net energy gain in algal cultivation for biodiesel production. Bioresour Technol 114:294-302

4. Bermu'dez V, Lujan JM, Pla B, Linares WG (2011) Comparative study of regulated and unregulated gaseous emissions during NEDC in a light-duty diesel engine fuelled with Fischer Tropsch and biodiesel fuels. Biomass Bioenergy 35:789-798

5. Bohlmann GM (2005) Biorefinery process economics. In: Paper presented at the World Congress on Industrial Biotechnology and Bioprocessing

6. Briggs M (2004) Widescale biodiesel production from algae. http://www.unh.edu/p2/biodiesel/article_alge.html. Retrieved Aug 2007

7. Chen L, Liu T, Zhang W, Chen X, Wang J (2012) Biodiesel production from algae oil high in free fatty acids by two-step catalytic conversion. Bioresour Technol 111:208-214
8. Chen S, Wen Z, Liao W, Liu C, Kincaid RL, Harrison JH (2005) Studies into using manure in a biorefinery concept. Appl Biochem Biotechnol 124(1-3):999-1016

9. Christensen BH, Nielsen C (2005) Biorefineries with optimal carbon utilization for liquid bio-fuels. In: Paper presented at the First International Biorefinery Workshop

10. Clark JH, Budarin V, Deswarte FEI, Hardy JJE, Kerton FM, Hunt $\mathrm{AJ}$ (2006) Green chemistry and the biorefinery: a partnership for a sustainable future. Green Chem 8:853-860

11. Corthals S, Noyen JV, Geboers J, Vosch T, Liang D, Ke X, Hofkens J, Tendeloo GV, Jacobs P, Sels B (2012) The beneficial effect of $\mathrm{CO} 2$ in the low temperature synthesis of high quality carbon nanofibers and thin multiwalled carbon nanotubes from CH4 over Ni catalysts. Carbon 50:372-384

12. Delft University of Technology (2003) Annual report of Delft University of Technology (TUDelft). Technology Assessment Section, Delft, Netherlands

13. Demirbas A, Demirbas MF (2011) Importance of algae oil as a source of biodiesel. Energy Convers Manag 52:163-170

14. Dewulf J, Langenhove HV (eds) (2006) Renewables-based technology: sustainability assessment. Wiley, Chichester. Directory: biodiesel from algae oil (n.d.). Retrieved Aug 2007

15. Ellison K (2007) Biodiesel boom heading toward Wall street. Business 2.0 Magazine. http://money.cnn.com/2007/09/25/ technology/biodieselboom.biz2/?postversion07092609. Retrieved Sept 2007

16. Elnashaie SSEH, Elshishini SS (1996) Dynamic modelling, bifurcation and chaotic behaviour of gas-solid catalytic reactors. Gordon and Breach, Amsterdam

17. Elnashaie SSEH, Garhyan P (2003) Conservation equations and modelling of chemical and biochemical processes. Marcel Dekker, New York

18. Elnashaie SSEH, Grace JR (2007) Complexity, bifurcation and chaos in natural and man-made lumped and distributed systems. Chem Eng Sci 62(13):3295-3325

19. Elnashaie SSEH, Uhlig F (2007) Numerical techniques for chemical and biological engineers using MATLAB. Springer, New York

20. Ferrell J, Sarisky-Reed V (2008) National Algal Biofuels Technology Roadmap. In: A technology roadmap resulting from the National Algal Biofuels Workshop. December 9-10, 2008, College Park, Maryland (Publication date May 2010)

21. Fiksel J (2006) Sustainability and resilience: toward a systems approach. Sci Pract Policy 2(2):14-21

22. Food and Agriculture Organization of the United Nations (1997) A system approach to biogas technology. http://www.fao.org/sd/ EGdirect/EGre0022.htm. Retrieved Aug 2007

23. Gallagher BJ (2011) The economics of producing biodiesel from algae. Renew Energy 36:158-162

24. Geist HJ (2011) Linkages of sustainability. Bioscience 61(4):328-330

25. Governmental and industry partnerships for developing biorefineries (2004) Biobased Fuels, Power and Products Newsletter, pp 1-2

26. Halog A, Mao H (2011) Assessment of hemicellulose extraction technology for bioethanol production in the emerging bioeconomy. Int J Renew Energy Technol 2(3):223-239

27. Hens L (ed) (2005) The World Summit on Sustainable Development: the Johannesburg Conference. Springer, Dordrecht

28. Ho Sh, Chen Ch, Lee DJ, Chang JS (2011) Perspectives on microalgal CO2-emission mitigation systems-a review. Biotechnol Adv 29:189-198

29. Horbach J (ed) (2005) Indicator systems for sustainable innovation (sustainability and innovation). Physica-Verlag, Heidelberg

30. Hramov AE, Koronovskii AA (2005) Generalized synchronization: a modified system approach. Physics Review E (Stat Nonlinear Soft Matter Phys) 71(6):1-4

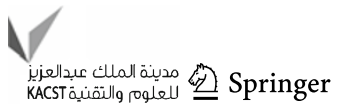


31. Institution of Chemical Engineers (2002) The sustainability metrics: sustainable development progress metrics recommended for use in the process industries. http://nbis.org/nbisresources/ metrics/triple_bottom_line_indicators_process_industries.pdf

32. Integrated biorefineries (n.d.) (2007) http://www1.eere.energy. gov/biomass/integrated_biorefineries.html. Retrieved Aug 2007

33. Kochergin V, Kearney M (2006) Existing biorefinery operations that benefit from fractal-based process intensification. Appl Biochem Biotechnol 130(1-3):349-360

34. Koltun P (2010) Materials and sustainable development. Prog Nat Sci: Mater Int 20:16-29

35. Krohn BJ, McNeff CV, Yan B, Nowlan D (2011) Production of algae-based biodiesel using the continuous catalytic Mcgyan process. Bioresour Technol 102:94-100

36. Lapuerta M, Armas O, Hernández JJ, Tsolakis A (2010) Potential for reducing emissions in a diesel engine by fuelling with conventional biodiesel and Fischer-Tropsch diesel. Fuel 89:3106-3113

37. Lou Z, Chen C, Huang H, Zhao D (2006) Fabrication of Y-junction carbon nanotubes by reduction of carbon dioxide with sodium borohydride. Diamond Relat Mater 15(10):1540-1543

38. Magrez A, Seo JW, Kuznetsov VL, Forro L (2007) Evidence of an equimolar $\mathrm{C} 2 \mathrm{H} 2-\mathrm{CO} 2$ reaction in the synthesis of carbon nanotubes. Angew Chem Int Ed 46(3):441-444

39. Makower J, Fleischer D (2003) Sustainable consumption and production: Strategies for accelerating positive change. Environmental Grantmakers Association Nanotechnology: Opportunities and challenges (n.d.), New York. http://nano.nd.edu/ ESTS40403/index.html. Retrieved Aug 2007

40. Odlare M, Nehrenheim E, Ribé V, Thorin E, Gavare M, Grube M (2011) Cultivation of algae with indigenous species-potentials for regional biofuel production. Appl Energy 88:3280-3285

41. Omer AM (2008) Energy, environment and sustainable development. Renew Sustain Energy Rev 12:2265-2300

42. Realff MJ, Abbas C (2004) Industrial symbiosis, refining the biorefinery. J Indust Ecol 7(3-4):5-9 (Bull Sci Technol Soc)

43. Regalbuto JR (2011) The sea change in US biofuels' funding: from cellulosic ethanol to green gasoline. Biofuels Bioprod Biorefin 5(5):495-504

44. Rogers PL, Eon YJ, Svenson CJ (2005) Application of biotechnology to industrial sustainability. Process Saf Environ Protect 83(B6):499-503

45. Romar H, Lahti R, Tynjälä P, Lassi U (2011) Co and Fe catalysed Fischer-Tropsch synthesis in biofuel production. Top Catal 54(16-18): 1302-1308

46. Rotmans J, van Asselt MBA, de Bruin AJ, den Elzen MGJ, de Greef J, Hilderink HBM (1994) Global change and sustainable development: A modelling perspective for the next decade. National Institute for Public Health and the Environment, Bilthoven
47. Sazdanoff N (2006) Modeling and simulation of the algae to biodiesel fuel cycle. Unpublished honors undergraduate thesis, Ohio State University

48. Seok H, Nof ShY, Filip FG (2012) Sustainability decision support system based on collaborative control theory. Annu Rev Control 36:85-100

49. Shahid EM, Jamal Y (2011) Production of biodiesel: a technical review. Renew Sustain Energy Rev 15:4732-4745

50. Sheehan J, Dunahay TG, Benemann JR, Roessler PG, Weissman JC (1998) A look back at the US Department of Energy's Aquatic Species Program: biodiesel from algae. National Renewable Energy Laboratory, Golden

51. Sheppard AW, Gillespie L, Hirsch M, Begley C (2011) Biosecurity and sustainability within the growing global bioeconomy. Curr Opin Environ Sustain 3:4-10

52. Subhadra BG (2011) Macro-level integrated renewable energy production schemes for sustainable development. Energy Policy 39(4):2193-2198

53. Subramanian K (2000) The system approach. Hanser Gardner, Cincinnati

54. Taniquchi I, Tabata D, Kusuda H, Koga T, Sotomura T (2003) Construction of bio-fuel cells using catalytic electrodes for oxidation of sugars and reduction of oxygen. In: Paper presented at the 204th meeting of the Electro Chemical Society

55. Trazil D, Ma G, Beloff BR (2003) Sustainability metrics. In: Paper presented at the 11th International Conference of Greening of Industry Network, Innovation for Sustainability

56. Tsang SC, Harris PJF, Green MLH (1993) Thinning and opening of carbon nanotubes by oxidation using carbon dioxide. Nature 362:520-522

57. Verdejo R, Lamoriniere S, Cottam B, Bismarck A, Shaffer M (2007) Removal of oxidation debris from multi-walled carbon nanotubes. Chem Commun 5:513-515

58. Von Bertalanffy L (1976) General system theory: foundations, development, applications. George Braziller, New York

59. Way LA, Wilson G (eds) (2005) Managing for tomorrow: resource-based communities \& the environment. University of Northern British Columbia, Prince George

60. Wen Q, Qian W, Wei F, Liu Y, Ning G, Zhang Q (2007) CO2assisted SWNT growth on porous catalysts. Chem Mater 19(6):1226-1230

61. Worden RM, Grethlein AJ, Jain MK, Datta R (1991) Production of butanol and ethanol from synthesis gas via fermentation. Fuel 70:615-619

62. Xu X, Huang S (2007) Carbon dioxide as a carbon source for synthesis of carbon nanotubes by chemical vapor deposition. Mater Lett 61:4235-4237 